\section{(6) OPEN ACCESS}

\title{
Return to play after thigh muscle injury in elite football players: implementation and validation of the Munich muscle injury classification
}

\author{
Jan Ekstrand, ${ }^{1}$ Carl Askling, ${ }^{2,3}$ Henrik Magnusson, ${ }^{1}$ Kai Mithoefer ${ }^{4}$
}

${ }^{1}$ Department of Medical and Health Sciences, Football Research Group, Linköping University, Linköping, Sweden ${ }^{2}$ The Swedish School of Sport and Health Sciences, Karolinska Institute, Stockholm, Sweden

${ }^{3}$ The Section of Orthopaedics and Sports Medicine, Department of Molecular Medicine and Surgery, Karolinska Institute, Stockholm, Sweden

${ }^{4}$ Harvard Vanguard Medical Associates, Harvard Medical School, Boston, Massachusetts, USA

\section{Correspondence to}

Professor Jan Ekstrand, Department of Medical and Health Sciences, Football Research Group, Linköping University, Solstigen 3 , Linköping S-589 43, Sweden; jan.ekstrand@telia.com

Received 15 December 2012 Revised 6 April 2013 Accepted 13 April 2013 Published Online First 5 May 2013

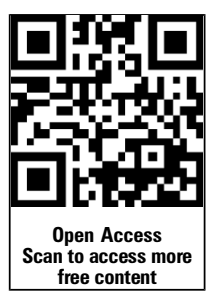

To cite: Ekstrand J, Askling $\mathrm{C}$, Magnusson $\mathrm{H}$, et al. Br J Sports Med 2013;47:769-774.

\section{ABSTRACT}

Background Owing to the complexity and

heterogeneity of muscle injuries, a generally accepted classification system is still lacking.

Aims To prospectively implement and validate a novel muscle injury classification and to evaluate its predictive value for return to professional football.

Methods The recently described Munich muscle injury classification was prospectively evaluated in 31 European professional male football teams during the 2011/2012 season. Thigh muscle injury types were recorded by team medical staff and correlated to individual player exposure and resultant time-loss.

Results In total, 393 thigh muscle injuries occurred. The muscle classification system was well received with a $100 \%$ response rate. Two-thirds of thigh muscle injuries were classified as structural and were associated with longer lay-off times compared to functional muscle disorders $(p<0.001)$. Significant differences were observed between structural injury subgroups (minor partial, moderate partial and complete injuries) with increasing lay-off time associated with more severe structural injury. Median lay-off time of functional disorders was 5-8 days without significant differences between subgroups. There was no significant difference in the absence time between anterior and posterior thigh injuries.

Conclusions The Munich muscle classification demonstrates a positive prognostic validity for return to play after thigh muscle injury in professional male football players. Structural injuries are associated with longer average lay-off times than functional muscle disorders. Subclassification of structural injuries correlates with return to play, while subgrouping of functional disorders shows less prognostic relevance. Functional disorders are often underestimated clinically and require further systematic study.

\section{INTRODUCTION}

Muscle injuries represent one-third of all injuries in football and cause one-quarter of total injury absence. ${ }^{1}$ Over $50 \%$ of muscle injuries affect the thigh muscles, and hamstring muscle injuries are the most common injury subtype representing $12 \%$ of all injuries. ${ }^{1}$ A professional male football team with 25 players suffers about five hamstring injuries and three quadriceps injuries each season, resulting in 130 lost football days. ${ }^{1}$

The aim is to return the player to training and matches as soon as possible. Prognostic information is vital for the medical staff to address questions from players, coaches, managers, media and agents regarding return to play.
The fact that muscle injuries present a heterogeneous group of injury types, locations, severities and sizes, makes prognoses about healing times and rehabilitation difficult. ${ }^{1-5}$

A radiological classification system of muscle injuries introduced by Peetrons ${ }^{6}$ is frequently used for imaging; recently, Ekstrand et $a l^{2}$ showed that MRI can be helpful in verifying the diagnosis of hamstring injuries and that radiological grading is associated with lay-off times after injury.

However, a clinical classification system correlating clinical grading with absence is presently not available.

Recently, the 'Munich muscle injury classification system was introduced as a new terminology and classification system of muscle injuries' ${ }^{7}$ This clinical system classifies muscle injuries into functional and structural-mechanical injuries, where functional disorders are fatigue-induced or neurogenic injuries causing muscle dysfunction, while structural-mechanical injuries are tears of muscle fibres. ${ }^{7}$

The aim of the present study was to implement the Munich classification system in male elite-level football teams in Europe (teams from Union of European Football Associations (UEFA) Champions League and English Premier League) and to evaluate if the classification system is applied and received well by the teams' medical staff. A further aim was to prospectively evaluate the classification system as a predictor of return to play. A third aim was to provide normative data for the frequency of muscle injuries in the different classification groups as well as to analyse if the classification system could be useful both for anterior and posterior thigh muscle injuries.

We hypothesised that the classification system is well received and readily applicable by football medical teams and that the distribution of lay-off days is different across categories of the classification.

\section{MATERIAL AND METHODS}

Study population

A prospective cohort study of men's professional football in Europe has been carried out since 2001, the UEFA Champions League (UCL) study. ${ }^{8}$ For the purpose of this substudy, 31 European professional teams (1032 players) were followed over the 2011/2012 season between July 2011 and May 2012. All contracted players in the first teams were invited to participate in the study.

\section{Study design and definitions}

The full methodology and the validation of the UCL injury study design are reported elsewhere. ${ }^{9}$ The study design followed the consensus on 
definitions and data collection procedures in studies of football injuries. ${ }^{9}{ }^{10}$ An overview of the general definitions is seen in table 1. Specifically for this study, a thigh muscle injury was defined as 'a traumatic distraction or overuse injury to the anterior or posterior thigh muscle groups leading to a player being unable to fully participate in training or match play'. Contusions, haematomas, tendon ruptures and chronic tendinopathies were excluded.

\section{Data collection}

Player baseline data were collected at the start of the season. Individual player exposure in training and matches was registered by the clubs on a standard exposure form and sent to the study group on a monthly basis. Team medical staff recorded thigh muscle injuries on a standard injury form that was sent to the study group each month. The thigh injury form is an A4 page consisting of ticking boxes for type, location, mechanisms of injuries as well as diagnostic procedures (clinical examination, imaging by MRI or ultrasonography) and treatments. All injuries resulting in a player being unable to fully participate in training or match play (ie, time-loss injuries) were recorded, and the player was considered injured until the team medical staff allowed full participation in training and availability for match selection. All injuries were followed until the final day of rehabilitation. To ensure high reliability of data registration, all teams were provided with a study manual containing definitions and describing the procedures used to record data, including fictive examples. To avoid language problems, the manual and the study forms were translated from English into five other languages: French, Italian, Spanish, German and Russian. In addition, all reports were checked each month by the study group, and feedback was sent to the teams in order to correct any missing or unclear data. While each team received detailed instructions on how to standardise the process of data collection, potential limitations included the risk for observer bias from the lack of independent injury classification and the evaluation of return to play performed by the same team medical staff.

\section{Magnetic resonance imaging}

For the purpose of this study, the clubs were instructed to perform the initial MRI examination within $24-48 \mathrm{~h}$ of the injury event. The MRI machine should not be older than 5 years and should have a field strength of at least $1.5 \mathrm{~T}$. The minimum MR sequences should include axial and coronal planes using T1, T2 with fat saturation and/or STIR sequences. A MRI Thigh Injury Report Form was created with information about date of imaging, the name of the radiologist evaluating the images, MR sequences used, muscles involved and severity of injury.

For severity classification, a modification of Peetrons radiological classification ${ }^{6}$ was utilised with the following grading system: grade 0-negative MRI without any visible pathology; grade 1-oedema, but no architectural distortion; grade 2-architectural disruption indicating partial tear; and grade 3-total muscle or tendon rupture. All radiologists used the same standard evaluation protocol.

Table 1 Operational definitions

\begin{tabular}{|c|c|}
\hline Injury & $\begin{array}{l}\text { Injury resulting from playing football and leading to a player being unable to fully participate in future training or match play } \\
\text { (ie, time-loss injury) }\end{array}$ \\
\hline Thigh muscle injury & $\begin{array}{l}\text { A traumatic distraction or overuse injury to the anterior or posterior thigh muscle groups leading to a player being unable to fully } \\
\text { participate in training or match play }\end{array}$ \\
\hline Rehabilitation & A player was considered injured until team medical staff allowed full participation in training and availability for match selection \\
\hline Lay-off & Number of days until the player resumed full team training \\
\hline Re-injury & $\begin{array}{l}\text { Injury of the same type and at the same site as an index injury occurring no more than } 2 \text { months after a player's return to full } \\
\text { participation from the index injury }\end{array}$ \\
\hline Functional muscle disorders & Painful muscle disorder without evidence of muscle fibre damage. \\
\hline Fatigue-induced muscle disorder & $\begin{array}{l}\text { Circumscript longitudinal increase of muscle tone due to over-exertion, change of playing surface, or change in training patterns. } \\
\text { Pain increased with activity. Increased muscle tone is noted in the affected muscle area with mild, dull pain. 'Dry muscle' changes } \\
\text { without oedema formation are typical on imaging modalities. }\end{array}$ \\
\hline Delayed Onset Muscle Soreness (DOMS) & $\begin{array}{l}\text { More generalised muscle pain following unaccustomed, eccentric deceleration movements with possible associated sarcomeric } \\
\text { ruptures of Z-discs. Presents as dull, aching pain in the affected muscle groups usually peaking within } 24-72 \mathrm{~h} \text { after initiating } \\
\text { activity. Pain is present at rest and less severe or absent with concentric muscle activity. No or minimal signal changes are } \\
\text { observed in the involved muscle on imaging. }\end{array}$ \\
\hline $\begin{array}{l}\text { Neuromuscular muscle disorder-spine } \\
\text { related }\end{array}$ & $\begin{array}{l}\text { Circumscript longitudinal increase of muscle tone due to functional or structural spinal disorder (including sacroiliac joint). } \\
\text { Subjective tightness and pain with intense activity, stretching and palpation. Sometimes associated with altered skin sensation. } \\
\text { Increased muscle tone over the entire muscle length on palpation. Discrete 'seam-like' fluid accumulation between muscle and } \\
\text { fascia throughout the entire length of the involved muscle on imaging. }\end{array}$ \\
\hline $\begin{array}{l}\text { Neuromuscular muscle disorder-muscle } \\
\text { related }\end{array}$ & $\begin{array}{l}\text { Circumscript spindle-shaped area of increased muscle firmness. Possibly resulting from dysfunctional neuromuscular control. } \\
\text { Increasing pulling and cramp-like sensation within muscle. Aggravated with activity and improved by rest and gentle stretch. } \\
\text { Spindle-like, longitudinal induration within the affected muscle belly on palpation. Spindle-like muscle oedema without } \\
\text { haematoma or focal muscle defect on imaging. }\end{array}$ \\
\hline Structural muscle disorders & Any acute indirect muscle disorder with macroscopic evidence of muscle fibre damage. \\
\hline Partial muscle injury-minor & $\begin{array}{l}\text { Structural muscle injury involving only Intra-Fascicle Tear. Acute, sharp pain often at muscle-tendon junction. Focal pain on } \\
\text { palpation usually without palpable defect. No visible haematoma. Aggravation of pain by stretching and palpation. Intra-fascicle } \\
\text { haematoma and focal muscle defect on imaging with intact surrounding fascia. }\end{array}$ \\
\hline Partial muscle injury-moderate & $\begin{array}{l}\text { Structural muscle injury involving Inter-Fascicle or Muscle Bundle Tear. Acute severe, stabbing pain often at muscle-tendon } \\
\text { junction, often associated with fall from reflectory unloading. Palpable, defined defect in affected muscle, painful to touch and } \\
\text { gentle stretch. Quickly developing, visible haematoma. Defect of muscle, fascia and haematoma visible on imaging. }\end{array}$ \\
\hline $\begin{array}{l}\text { Subtotal/complete muscle injury/ } \\
\text { tendinous avulsion }\end{array}$ & $\begin{array}{l}\text { Structural muscle injury involving the subtotal }(>90 \%) \text { or complete muscle diameter or complete tendinous avulsion. Acute severe } \\
\text { pain ('someone kicked/hit me') and reflectory unloading. Severe pain with passive motion and palpation. Immediate functional } \\
\text { deficit with development of extensive haematoma. Large palpable defect often at the muscle-tendon junction or retraction of } \\
\text { avulsed muscle. Obvious muscle defect or tendinous avulsion and with haematoma formation is observed on imaging. }\end{array}$ \\
\hline
\end{tabular}




\section{Injury evaluation}

Of the 393 injuries recorded during the study period, all (100\%) underwent physical examination, 215 (55\%) were examined by MRI and 75 (35\%) of these also had concomitant initial ultrasound. One-hundred and seven injuries (27\%) were examined exclusively by initial ultrasound without MRI, and $70(18 \%)$ were examined clinically without the use of any imaging. Information about examination method was missing for one injury.

\section{Implementation and validation of the Munich muscle injury classification}

During the season 2011/2012, ticking boxes for injury classification according to the Munich system were added to the thigh injury card. The team medical staffs were asked to tick one of the following alternatives: Fatigue-induced muscle disorder, delayed onset muscle soreness, neuromuscular muscle disorder-spine related, neuromuscular disorder-muscle related, partial muscle injury-minor, partial muscle injury-moderate, subtotal/complete muscle injury/tendinous avulsion. The definitions of functional and structural muscle disorders and their subgroups (as they appeared in the study manual) are shown in table 1 . Validity presents the extent to which a concept, conclusion or measurement is well-founded and corresponds accurately to reality. The validation process of the classification was therefore designed to evaluate whether the concept and grading of the classification corresponded to clinically relevant parameters such as the lay-off times of the injured players.

\section{Statistical analyses}

Lay-off days are presented with median $(\mathrm{Md})$ and IQR. $\chi^{2}$ Test was used to analyse the association between categorical data. Kolmogorov-Smirnov test (D) was used to test for normality in lay-off days, and Levene's test (F) was used to test for homogeneity of variance in subgroups. Non-parametric methods, Mann-Whitney U-test (U) and Kruskal-Wallis test $(\mathrm{H})$ were used in this study to analyse differences in lay-off days between independent subgroups. All tests were two-sided and the significance level was set at $\mathrm{p}<0.05$. All statistical analyses were made in IBM SPSS Statistics V.19.0 (IBM Corp, Armonk, New York, USA). The study design underwent an ethical review and was approved by the UEFA Football Development Division and the Medical Committee.

\section{RESULTS}

Of the 393 thigh muscle injuries reported during the study period, all (100\%) injury forms included injury classification according to the Munich system.

Overall, $263(67 \%)$ of the thigh injuries were classified as structural and $130(33 \%)$ as functional. Two-hundred and ninety-eight (76\%) injuries affected the posterior thigh; 193 $(65 \%)$ were classified as structural injuries and $105(35 \%)$ as functional disorders. Ninety-five (24\%) injuries affected the anterior thigh; 70 (74\%) were classified as structural injuries and $35(26 \%)$ as functional disorders. There was no significant association between classification (functional/structural) and location (anterior/posterior), $\chi^{2}(1)=2.59, \mathrm{p}=0.108$.

The distribution of lay-off days, in both structural injuries and functional disorders, was significantly non-normal, $\mathrm{D}(263)=0.21, \mathrm{p}<0.001$ and $\mathrm{D}(130)=0.24, \mathrm{p}<0.001$, respectively. Levene's test also indicated a significant difference in variance in the subgroups, $\mathrm{F}(1,391)=33.80, \mathrm{p}<0.001$.
The number of lay-off days was significantly higher in structural injuries (Md 16, IQR 16 days) compared to functional disorders (Md 6, IQR 6 days), $\mathrm{U}=6184.5, \mathrm{z}=-10.31, \mathrm{r}=-0.52$, $\mathrm{p}<0.001$. The difference in lay-off days between structural injuries and functional disorders, within both anterior (Md 14, IQR 16 days vs Md 7, IQR 9 days) and posterior (Md 16, IQR 15 days vs Md 6, IQR 5 days) thigh injuries, was also significant, $\mathrm{U}=446.5, \mathrm{z}=-3.62, \mathrm{r}=-0.37, \mathrm{p}<0.001$ and $\mathrm{U}=3229.5$, $\mathrm{z}=-9.72, \mathrm{r}=-0.56, \mathrm{p}<0.001$, respectively. However, there was no significant difference in lay-off days between anterior (Md 12, IQR 15 days) and posterior (Md 12, IQR 14 days) thigh injuries overall, $\mathrm{U}=14004.0, \mathrm{z}=-0.16, \mathrm{r}=-0.01, \mathrm{p}=0.88$.

Detailed classification-specific normative data are presented in table 2 and figure 1.

There was a significant difference in lay-off days between the subgroups of structural injuries, $\mathrm{H}(2)=93.91, \mathrm{p}<0.001(\mathrm{Md} 13$, IQR 10 days for minor partial muscle tears (1), Md 32, IQR 24 days for moderate partial muscle tears (2) and Md 60, IQR 5 days for subtotal/complete muscle injury/tendinous avulsion (3)). Pairwise comparisons were conducted to follow-up the significant difference among the subgroups, controlling for type I error across tests by using Bonferroni approach. The results of these tests indicated that the number of lay-off days was significantly higher in both subgroups (2) and (3) compared to subgroup (1). However, lay-off days were not significantly affected by the subgroups of functional disorders, $\mathrm{H}(3)=4.49, \mathrm{p}=0.21$. Median lay-off for the subgroups was between 4.5 and 8 days.

Information about the performed examinations was available in all except one injury. MRIs were performed in 36/130 (28\%) of functional disorders and in 179/262 (68\%) of structural injuries. MRI forms for 52 of the 215 MRI examinations (24\%) were received from 14 of the 31 clubs. All 12 injuries, clinically classified as functional disorders, were reported to be either of radiological grade 0 (no MRI pathology) (17\%) or grade 1 (oedema without visible tears) (83\%) and without signs of muscle ruptures on MRI.

Thirteen injuries were clinically classified as moderate partial muscle tears; $10(77 \%)$ were reported as MRI grade 2 ; and 3 (23\%) were reported as MRI grade 1.

The 27 injuries clinically classified as minor partial muscle tears showed mixed MRI gradings. The majority (81\%) were classified as either grade $0 \quad(n=1)$ or grade $1 \quad(n=21)$ with muscle tears reported in only 5 (19\%).

The radiological size of the tears was only reported in 9 $(60 \%)$ cases: $4(80 \%)$ in minor and $5(50 \%)$ in moderate partial muscle tears. The mean extent in millimetres of the minor partial muscle tears in $\mathrm{z}, \mathrm{x}$ and $\mathrm{y}$ direction was $26 \pm 11$ (range

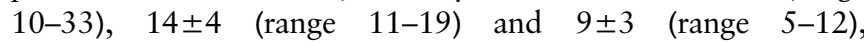
respectively.

\section{Primary injuries versus re-injuries}

Forty-nine injuries (12\%) were classified as re-injuries (injury of the same type and at the same site as an index injury occurring no more than 2 months after a player's return to full participation from the index injury). No significant association between injury classification and re-injury rate could be found, $\chi^{2}(1)$ $=0.005, \mathrm{p}=0.95$. The re-injury rate was $33 / 263(13 \%)$ within structural injuries $(13 \%$ in minor and $12 \%$ in moderate partial muscle tears, and $20 \%$ in subtotal/complete muscle injury/tendinous avulsion) and 16/130 (12\%) within functional disorders (10\% in fatigue-induced muscle disorders and $18 \%$ in both muscle-related and spine-related neuromuscular disorders). Only seven $(5 \%)$ of the initial functional disorders developed into secondary structural injuries within 2 months of the primary injury. 
Table 2 Lay-off days by thigh muscle location and Munich muscle classification system

\begin{tabular}{|c|c|c|c|c|c|c|c|c|c|c|c|c|c|}
\hline & \multirow[b]{2}{*}{ Munich muscle classification system } & \multirow[b]{2}{*}{ Mean } & \multirow[b]{2}{*}{ SD } & \multicolumn{2}{|c|}{$95 \% \mathrm{Cl}^{*}$} & \multirow[b]{2}{*}{ Median } & \multirow[b]{2}{*}{ Q1 } & \multirow[b]{2}{*}{ Q3 } & \multirow[b]{2}{*}{ Min } & \multirow[b]{2}{*}{ Max } & \multirow[b]{2}{*}{$\mathrm{N}$} & \multicolumn{2}{|c|}{$\%$ Within } \\
\hline & & & & Lower & Upper & & & & & & & Loct & Class \\
\hline \multirow[t]{12}{*}{ Anterior } & Functional & & & & & & & & & & & & \\
\hline & Fatigue-induced muscle disorders & 7.9 & 5.7 & 5.2 & 10.5 & 6.5 & 2.5 & 12.0 & 1 & 19 & 20 & 21.1 & 80.0 \\
\hline & Delayed onset muscle soreness & N/A & N/A & N/A & N/A & N/A & N/A & N/A & N/A & N/A & 0 & 0.0 & 0.0 \\
\hline & Spine-related neuromuscular muscle disorders & 4.0 & N/A & N/A & N/A & 4.0 & 4.0 & 4.0 & 4 & 4 & 1 & 1.1 & 4.0 \\
\hline & Muscle-related neuromuscular muscle disorders & 13.5 & 8.7 & -0.3 & 27.3 & 11.0 & 8.5 & 18.5 & 6 & 26 & 4 & 4.2 & 16.0 \\
\hline & Total functional anterior & 8.6 & 6.4 & 6.0 & 11.2 & 7.0 & 3.0 & 12.0 & 1 & 26 & 25 & 26.3 & 100.0 \\
\hline & Structural & & & & & & & & & & & & \\
\hline & Minor partial muscle tears & 13.8 & 17.5 & 8.7 & 18.8 & 11.0 & 7.0 & 16.0 & 2 & 124 & 49 & 51.6 & 70.0 \\
\hline & Moderate partial muscle tears & 43.7 & 32.3 & 28.1 & 59.3 & 37.0 & 25.0 & 50.0 & 14 & 156 & 19 & 20.0 & 27.1 \\
\hline & Subtotal/complete muscle injury/tendinous avulsion & 71.5 & 16.3 & $\mathrm{~N} / \mathrm{A}$ & N/A & 71.5 & 60.0 & 83.0 & 60 & 83 & 2 & 2.1 & 2.9 \\
\hline & Total structural anterior & 23.5 & 27.1 & 17.1 & 30.0 & 14.0 & 9.0 & 25.0 & 2 & 156 & 70 & 73.7 & 100.0 \\
\hline & Total anterior & 19.6 & 24.4 & 14.6 & 24.6 & 12.0 & 7.0 & 22.0 & 1 & 156 & 95 & 100.0 & \\
\hline \multirow[t]{12}{*}{ Posterior } & Functional & & & & & & & & & & & & \\
\hline & Fatigue-induced muscle disorders & 7.9 & 8.0 & 5.9 & 9.9 & 6.5 & 4.0 & 9.0 & 1 & 58 & 62 & 20.8 & 59.0 \\
\hline & Delayed onset muscle soreness & 4.5 & 0.6 & 3.6 & 5.4 & 4.5 & 4.0 & 5.0 & 4 & 5 & 4 & 1.3 & 3.8 \\
\hline & Spine-related neuromuscular muscle disorders & 7.0 & 4.8 & 4.8 & 9.2 & 5.0 & 4.0 & 8.0 & 1 & 18 & 21 & 7.0 & 20.0 \\
\hline & Muscle-related neuromuscular muscle disorders & 13.8 & 22.6 & 2.6 & 25.1 & 7.5 & 5.0 & 10.0 & 2 & 100 & 18 & 6.0 & 17.1 \\
\hline & Total functional posterior & 8.6 & 11.4 & 6.4 & 10.8 & 6.0 & 4.0 & 9.0 & 1 & 100 & 105 & 35.2 & 100.0 \\
\hline & Structural & & & & & & & & & & & & \\
\hline & Minor partial muscle tears & 17.3 & 16.9 & 14.5 & 20.1 & 14.0 & 9.0 & 20.0 & 3 & 132 & 143 & 48.0 & 74.1 \\
\hline & Moderate partial muscle tears & 35.5 & 19.5 & 29.8 & 41.2 & 30.0 & 22.0 & 48.0 & 8 & 111 & 47 & 15.8 & 24.4 \\
\hline & Subtotal/complete muscle injury/tendinous avulsion & 56.3 & 4.5 & N/A & N/A & 56.0 & 52.0 & 61.0 & 52 & 61 & 3 & 1.0 & 1.6 \\
\hline & Total structural posterior & 22.4 & 19.5 & 19.6 & 25.1 & 16.0 & 11.0 & 26.0 & 3 & 132 & 193 & 64.8 & 100.0 \\
\hline & Total posterior & 17.5 & 18.3 & 15.4 & 19.6 & 12.0 & 6.0 & 20.0 & 1 & 132 & 298 & 100.0 & \\
\hline \multirow[t]{12}{*}{ Total } & Functional & & & & & & & & & & & & \\
\hline & Fatigue-induced muscle disorders & 7.9 & 7.4 & 6.2 & 9.5 & 6.5 & 3.0 & 10.0 & 1 & 58 & 82 & 20.9 & 63.1 \\
\hline & Delayed onset muscle soreness & 4.5 & 0.6 & 3.6 & 5.4 & 4.5 & 4.0 & 5.0 & 4 & 5 & 4 & 1.0 & 3.1 \\
\hline & Spine-related neuromuscular muscle disorders & 6.8 & 4.8 & 4.7 & 8.9 & 5.0 & 4.0 & 8.0 & 1 & 18 & 22 & 5.6 & 16.9 \\
\hline & Muscle-related neuromuscular muscle disorders & 13.8 & 20.6 & 4.7 & 22.9 & 8.0 & 5.0 & 11.0 & 2 & 100 & 22 & 5.6 & 16.9 \\
\hline & Total functional & 8.6 & 10.6 & 6.7 & 10.4 & 6.0 & 4.0 & 10.0 & 1 & 100 & 130 & 33.1 & 100.0 \\
\hline & Structural & & & & & & & & & & & & \\
\hline & Minor partial muscle tears & 16.4 & 17.1 & 14.0 & 18.9 & 13.0 & 8.0 & 18.0 & 2 & 132 & 192 & 48.9 & 73.0 \\
\hline & Moderate partial muscle tears & 37.9 & 24.0 & 32.0 & 43.8 & 32.0 & 24.0 & 48.0 & 8 & 156 & 66 & 16.8 & 25.1 \\
\hline & Subtotal/complete muscle injury/tendinous avulsion & 62.4 & 12.1 & 47.4 & 77.4 & 60.0 & 56.0 & 61.0 & 52 & 83 & 5 & 1.3 & 1.9 \\
\hline & Total structural & 22.7 & 21.8 & 20.0 & 25.3 & 16.0 & 10.0 & 26.0 & 2 & 156 & 263 & 66.9 & 100.0 \\
\hline & Total & 18.0 & 19.9 & 16.0 & 20.0 & 12.0 & 6.0 & 20.0 & 1 & 156 & 393 & 100.0 & \\
\hline
\end{tabular}

${ }^{*} 95 \% \mathrm{Cl}$ based on t-distribution and only calculated for means based on more than three injuries.

†Thigh injury location-anterior or posterior.

¥Thigh injury classification-functional or structural based on Munich muscle classification system.

Q1, 1st quartile (25\%); Q3, 3rd quartile (75\%); Min, minimum; Max, maximum; N/A, not applicable.

Figure 1 Days of absence after different groups of muscle injuries.

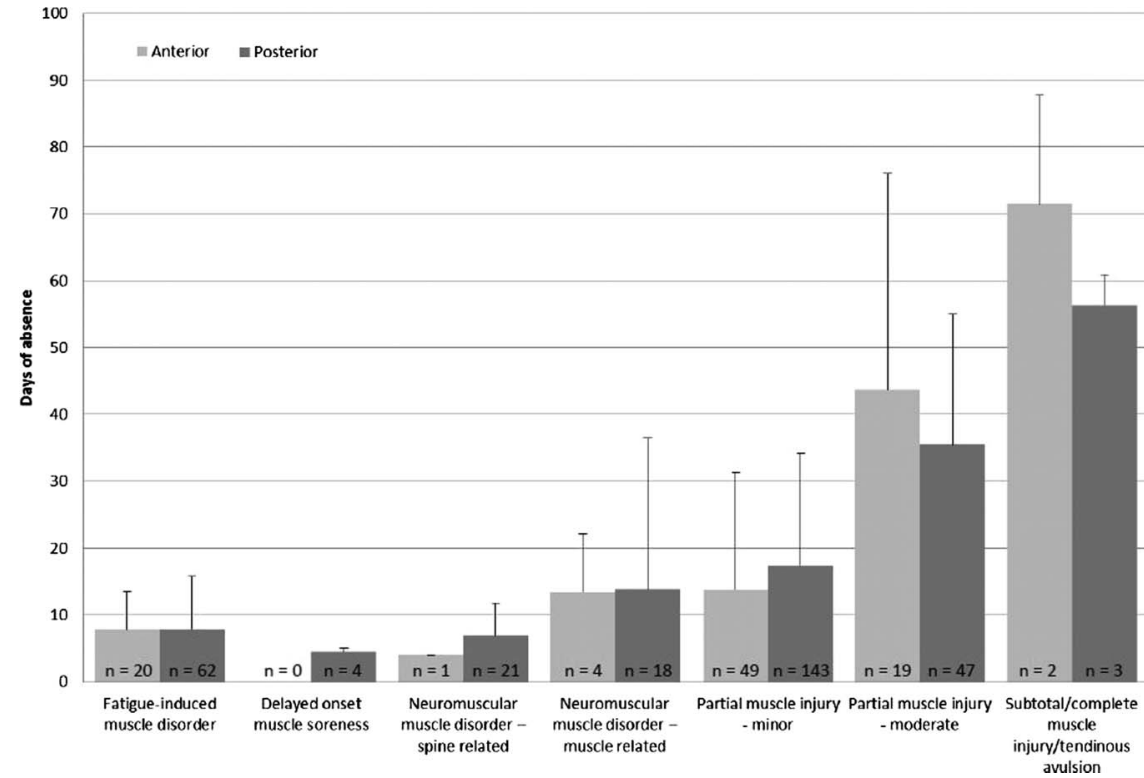




\section{DISCUSSION}

Muscle injuries present one of the most frequent and most relevant injuries in professional football accounting for a majority of time lost from competition. ${ }^{1}$ Owing to complex and heterogeneous presentation of these injuries, the development of a comprehensive muscle injury classification has traditionally been challenging. A critical aspect of a useful muscle injury classification is that it not only provides valid and practically relevant information to the treating medical practitioner but also easily applicable and accepted by medical staff. A main finding of the current study is that the implementation of the Munich muscle injury classification was highly successful, with full medical staff acceptance, and excellent injury data collection.

\section{Functional muscle disorders are clinically underestimated}

The present study showed a discrepancy between clinical and radiological classification. Among injuries classified both clinically and radiographically, $77 \%$ were clinically classified as structural tears, but radiological grading on MRI showed evidence of muscle tears in only $29 \%$ of injuries. This finding is in accordance with a recent study by Ekstrand et al, ${ }^{2}$ who showed that $70 \%$ of hamstring injuries seen in professional football show no signs of muscle fibre disruption on MRI. Still, these injuries are responsible for more than half of the muscle injury-related lay-off. ${ }^{2}$ The understanding of these most frequent muscle injuries/disorders with the highest impact on lay-off time is still limited and warrants further scientific evaluation. The differentiation of functional and structural muscle injuries introduced by the Munich classification is an important first step towards a more differentiated evaluation of this relatively undefined area of athletic muscle injury. The current study shows that functional muscle disorders are common, but associated with relatively short lay-off times, thereby providing useful information to medical staffs and athletes. Furthermore, our data demonstrate a low risk for the development of subsequent more severe re-injury after functional muscle disorders. Prospective specific investigation of functional muscle disorders with appropriate power is needed. Further systematic study is also required for developing reliable clinical and radiographic tools for differential diagnosis of functional muscle disorders and minor structural injury. However, this study suggests that for the purpose of predicting return to sport, differentiation of functional muscle disorders may not be as clinically relevant. Our finding that clinical classification tends to overestimate structural tears and underestimates functional disorders could be explained by the limited awareness of the high incidence of functional disorders in elite-level football. Since the Munich classification relies on a careful clinical examination and history of the injury, the skill of the clinician and a detailed understanding of the different disorders, there may be a distinct learning curve, and education and experience may become an important factor.

\section{Return to play is longer after structural injuries}

The ability to predict lay-off is very important for the injured player as well as the coaching staff. The Munich classification clearly shows a difference in return to play between structural and functional muscle injuries. This seems logical since by definition, structural injuries show macroscopic evidence of muscle fibre damage, and functional disorders show no such damage. Our study indicates that severity of the muscle injury directly affects the duration of the lay-off. Similarly, increased muscle injury severity on MRI has been associated with longer times to return to professional American Football ${ }^{2} 45$ 11-13

\section{Clinical classification relates to lay-off}

Another main finding of this study is that subgrouping of structural injuries into minor or moderate partial tears as well as total ruptures is clearly associated with lay-off time from football. By definition, validity is the extent to which a concept, conclusion or measurement is well-founded and corresponds accurately to the real world. Our finding that the concept and grading of the classification corresponded to the lay-off times of the injured players therefore validates the concept provided in the classification. Thus, our study validates the ability of the Munich muscle injury classification to differentiate between functionally relevant degrees of muscle injury and its usefulness for the prognosis of healing time. Similarly, the extent of muscle injury on MRI has been shown to have prognostic relevance as injuries involving $>50 \%$ of the muscle diameter were associated with longer lay-off times. ${ }^{11}{ }^{14}$ In our study, MRI was unable to detect the differences between moderate or minor structural injuries, suggesting that the Munich classification is more sensitive than MRI in detecting low-grade structural injury. Müller-Wohlfahrt et $a l^{7}$ postulated that secondary muscle bundles, with a diameter of $2-5 \mathrm{~mm}$, can be palpated by the experienced examiner, as well as suggested further studies to determine the size threshold between a minor and a moderate partial muscle tear. In the present study, MRI was unable to detect such small injuries $(<5 \mathrm{~mm})$ in any of the 52 injuries in either $\mathrm{x}, \mathrm{y}$ or $\mathrm{z}$ led. Previous studies ${ }^{15}{ }^{16}$ also noted that some clinically detected athletic muscle injuries are negative on 1.5 Tesla MRI and that these MRI-negative injuries resulted in faster return to competition. This suggests that MRI at the current resolution has limited sensitivity for the detection of minor muscle injury. Similarly, detection limits exist on clinical examination. Our study does not allow any definite conclusions of the tactile limit for the detection of minor muscle tears. Further systematic studies should try to better define the threshold for clinical detection of minor muscle injury possibly by correlation with high resolution MRI (3T or higher).

\section{The diagnosis and definition of the MRI-negative injuries are challenging}

Our study demonstrates that a negative MRI does not rule out clinically relevant muscle injury and that clinical diagnosis and management should be based on a combination of clinical history, physical examination and possibly radiographic evaluation. MRI grades $0-1$ injuries constitute the majority of muscle injuries in professional football athletes and include a spectrum of pathology such as minor structural injuries as well as functional muscle disorders. Differential diagnosis of these muscle disorders can be challenging and requires a thorough understanding of the Munich classification and strong clinical diagnostic skills. While grading of structural injuries in the Munich classification has prognostic relevance for return to play, subgrouping of functional disorders seems less relevant since lay-off times were similar between the different functional disorders. However, the differentiation of functional disorders may be important as it can impact the therapeutic approach. Interestingly, the average number of lay-off days is similar between minor structural and muscle-related neuromuscular functional disorders. Since the treatment approach is similar, it raises the question if the underlying pathologies could overlap. Could there be a neurological response to a minor tear such as a reciprocal inhibition or could a neurological inhibition facilitate the development of minor tears? This particular aspect of the Munich muscle injury classification requires further specific and 
powerful substudy and validation with detailed documentation of history, clinical exam, MRI, ultrasound and functional outcome parameters. An improved understanding of MRI grades $0-1$ muscle injuries will help to further optimise the management of these injuries and will help to develop evidencebased strategies for expedited and safe return to competition after athletic muscle injury. ${ }^{14} 1517$

\section{What are the new findings?}

In summary, the current study demonstrates the successful implementation of the Munich muscle injury classification in elite football players. In addition, it validates the following aspects:

- Structural injuries and functional disorders differ significantly in their lay-off times.

- Subgrouping of structural muscle injuries based on injury severity has positive prognostic relevance.

- Subgrouping of functional muscle disorders has less prognostic value.

\section{How might it impact on clinical practice?}

The Munich classification is helpful for clinicians to prognosticate return to play after muscle injury.

Acknowledgements The authors wish to thank the participating clubs, medical staffs and players.

Contributors JE designed the study, monitored data collection, analysed the data and drafted and revised the paper. He is the guarantor. KM, HM and CA interpreted data and drafted and revised the paper.

Funding This study was supported by grants from UEFA, EPL (English Premier League), the Swedish Centre for Research in Sports and Praktikertjänst AB.

Competing interests None.

Ethics approval UEFA Football Development Division and the Medical Committee. Provenance and peer review Not commissioned; externally peer reviewed.
Open Access This is an Open Access article distributed in accordance with the Creative Commons Attribution Non Commercial (CC BY-NC 3.0) license, which permits others to distribute, remix, adapt, build upon this work non-commercially, and license their derivative works on different terms, provided the original work is properly cited and the use is non-commercial. See: http://creativecommons.org/licenses/by-nc/3.0/

\section{REFERENCES}

1 Ekstrand J, Hägglund $M$, Waldén $M$. Epidemiology of muscle injuries in professional football (soccer). Am J Sports Med 2011;39:1226-32.

2 Ekstrand J, Healy JC, Walden $\mathrm{M}$, et al. Hamstring muscle injuries in professional football: the correlation of MRI findings with return to play. Br J Sports Med 2012;46:112-17

3 Koulouris G, Connell D. Imaging of hamstring injuries: therapeutic implications. Eur Radiol 2006;16:1478-87.

4 Askling C, Saartok T, Thorstensson A. Type of acute hamstring strain affects flexibility, strength, and time to return to pre-injury level. Br J Sports Med 2006;40:40-4.

5 Askling CM, Tengvar M, Saartok T, et al. Proximal hamstring strains of stretching type in different sports: injury situations, clinical and magnetic resonance imaging characteristics, and return to sport. Am J Sports Med 2008;36:1799-804.

6 Peetrons P. Ultrasound of muscles. Eur Radiol 2002;12:35-43.

7 Mueller-Wohlfahrt HW, Haensel L, Mithoefer K, et al. Terminology and classification of muscle injuries in sport: a consensus statement. Br J Sports Med 2012:47:342-50.

8 Ekstrand J, Hägglund $M$, Waldén $M$. Injury incidence and injury patterns in professional football: the UEFA injury study. Br J Sports Med 2011:45:553-8.

9 Hägglund M, Waldén M, Bahr R, et al. Methods for epidemiological study of injuries to professional football players: developing the UEFA model. Br J Sports Med 2005;39:340-6.

10 Fuller CW, Ekstrand J, Junge $A$, et al. Consensus statement on injury definitions and data collection procedures in studies of football (soccer) injuries. Br J Sports Med 2006;40:193-201.

11 Cohen SB, Towers JD, Zoga A, et al. Hamstring injuries in professional football players: magnetic resonance imaging correlation with return to play. Sports Health 2011:3:423-30.

12 Askling CM, Tengvar M, Saartok T, et al. Acute first-time hamstring strains during high-speed running: a longitudinal study including clinical and magnetic resonance imaging findings. Am J Sports Med 2007;35:197-206.

13 Malliaropoulos N, Isinkaye T, Tsitas K, et al. Reinjury after acute posterior thigh muscle injuries in elite track and field athletes. Am J Sports Med 2011;39:304-10.

14 Slavotinek JP. Muscle injury: the role of imaging in prognostic assignment and monitoring of muscle repair. Semin Musculoskelet Radiol 2010;14:194-200.

15 Verrall GM, Slavotinek JP, Barnes PG, et al. Diagnostic and prognostic value of clinical findings in 83 athletes with posterior thigh injury: comparison of clinical findings with magnetic resonance imaging documentation of hamstring muscle strain. Am J Sports Med 2003:31:969-73.

16 Gibbs NJ, Cross TM, Cameron M, et al. The accuracy of MRI in predicting recovery and recurrence of acute grade one hamstring muscle strains within the same season in Australian rules football players. J Sci Med Sport 2004;7:248-58.

17 Orchard J, Best TM, Verrall GM. Return to play following muscle strains. Clin J Sport Med 2005;15:436-41. 